\title{
Diffuse Cutaneous Systemic Scleroderma with Secondary Infection: A Case Report
}

\author{
Anastasia Wibianto* and Irene Dorthy Santoso \\ Department of Dermatovenereology, Faculty of Medicine, Tarumanagara University, Indonesia
}

*Corresponding author: Anastasia Wibianto, Department of Dermatovenereology, Faculty of Medicine, Tarumanagara University, Letjen S. Parman St., number 1, West Jakarta, Jakarta, 11470, Indonesia, Tel: +6281314857231

\begin{abstract}
Scleroderma (systemic sclerosis or SSc) is a connective tissue disease of unknown cause, characterized by skin and visceral organs fibrosis and microvascular abnormalities. The prevalence of these patients is relatively low with 50 300 cases per 1 million population and the incidence of 2.322.8 cases per 1 million population per year. The risk for women is higher than men with a ratio of $3: 1$ and majority age 30-50 years. Diagnosis is based on clinical features and investigations. Management in patients to reduce or eliminate complaints and improve organ function but cannot cure patients.

Case: Reported a case of diffuse cutaneous sitstemic scleroderma (dcSSc) with secondary infection in a 25-yearold woman. Diagnosis is based on American College of Rheumatology (ACR)/European League Against Rheumatism (EULAR) criteria which include serological components. Furthermore, an assessment of disability and function of the patient is performed using the Scleroderma Health Assessment Questionnaire (SHAQ). Treatment for the skin using topical antibiotic and vaseline album. Whereas the systemic treatment with vasodilators, immunosuppressive, antifibrotic, and proton pump inhibitors.
\end{abstract}

\section{Keywords}

SHAQ, Diffuse systemic scleroderma, Diffuse systemic sclerosis

\section{Introduction}

Scleroderma or systemic sclerosis is an autoimmune connective tissue disease characterized by excessive collagen build-up around the capillaries and affected tissues, such as the skin, lungs, heart, esophagus and kidneys [1]. The word scleroderma means "hard skin", [2-5] and crusting is the main symptom in all types of scleroderma $[3,4,6]$.

This disease is chronic and the cause is still unknown $[3,4,7]$. The prevalence of this patient is relatively low with 50-300 cases per 1 million population and an incidence of 2.3-22.8 cases per 1 million population per year, as well as a risk to women is higher than men with a 3:1 ratio, the majority of which are 30-50 years-old [8]. In America, the incidence of scleroderma is 9-19 cases per 1 million population annually with a prevalence of 286 cases per 1 million population per year [9].

In general, scleroderma is divided into two major groups, namely localized scleroderma/morphea and systemic scleroderma (SSc). Morphea usually only affects the skin although it can spread to muscles, joints, and bones but does not affect other organs. Meanwhile, systemic scleroderma is the most serious form of this disease which can affect the skin, muscles, joints, blood vessels, lungs, kidneys, heart, and other organs. Systemic scleroderma is divided into limited cutaneous systemic sclerosis (IcSSC) which usually presents with gastrointestinal symptoms and/or pulmonary hypertension that progresses more slowly; and diffuse cutaneous systemic sclerosis (dcSSc) which can affect the lungs, heart, renal, gastrointestinal tract and usually more aggressive.

The management of scleroderma itself is a challenge for clinicians. Current management is based on the type of scleroderma and multidisciplinary. Various treatment options are selected based on the affected organ $[4,5]$. Management of the patient is only to reduce or eliminate complaints and improve organ function, but cannot cure the patient [5]. An assessment of the patient's 
disability and function can be carried out using the Scleroderma Health Assessment Questionnaire (SHAQ) [10].

The following is a case report of a patient with diffuse systemic scleroderma with secondary infection manifestations.

\section{Case Report}

A woman, 25-years-old, with hardened skin complaints on her hands, feet, and neck since about 1 year, which is getting heavier these 3 months. The patient's skin is getting drier, especially in the areas of the forearms and lower legs, and white or black patches appear on the head, neck, back, abdomen, arms, and legs. The joints are getting stiff and enlarged, especially in the ankle area, the fingers, and toes. The patient also difficult to open the mouth because it is stiff and the neck is difficult to move. There was an abnormality in the fingertips which turned pale bluish suddenly when the patient had been in the cold for the last 3 months. Currently, patients find it difficult to carry out daily activities such as walking, eating, and bathing. The patient also complained that his skin became scabs, sometimes itchy and sore in almost all parts of the body. The patient also complained of lack of appetite and easily to full, so the patient's weight has decreased by 20 kilograms in the last 6 months. Sometimes the patient feels stomach acid rising into the mouth after eating. Other complaints were denied. A history like this or a previous chronic illness was denied. Family history of similar illness was denied.

On physical examination, the general condition was moderate, compos mentis, with blood pressure 90/60 $\mathrm{mmHg}$, pulse 97 beats/minute, respiration 20 times/ minute, and temperature $36.8^{\circ} \mathrm{C}$. On oral examination, a 2-finger trismus was found so that the teeth and oral mucosa were difficult to assess. Generalized dermatological examination showed xerotic skin with ectomy in the coli region, bilateral forearms, chest, abdomen, back, and bilateral legs. There are multiple hyperpigmented macules, plaque, diffuse, confluent, and sclerotic palpable in the bilateral arm, chest, abdomen, bilateral limbs, and back. In the facial region of the pars frontal, bilateral pars mastoid, neck, bilateral arms, chest, stomach, back, legs, hypopigmented to hyperpigmented macules, multiple, circumscribed forming a "salt and pepper" image. Puffy fingers are found all over the fingers. The total mRSS was 40 . The results of blood laboratory tests showed that the ESR was $90 \mathrm{~mm} /$ hour, C-Reactive Protein (CRP) was reactive, while other results were within normal limits. Serological tests for Rheumatoid Factor (RF) were positive, Antinuclear Antibody (ANA) was positive, Anti Scl-70 was positive (+). Postero-Anterior (PA) chest X-ray and electrocardiogram (EKG) within normal limits.

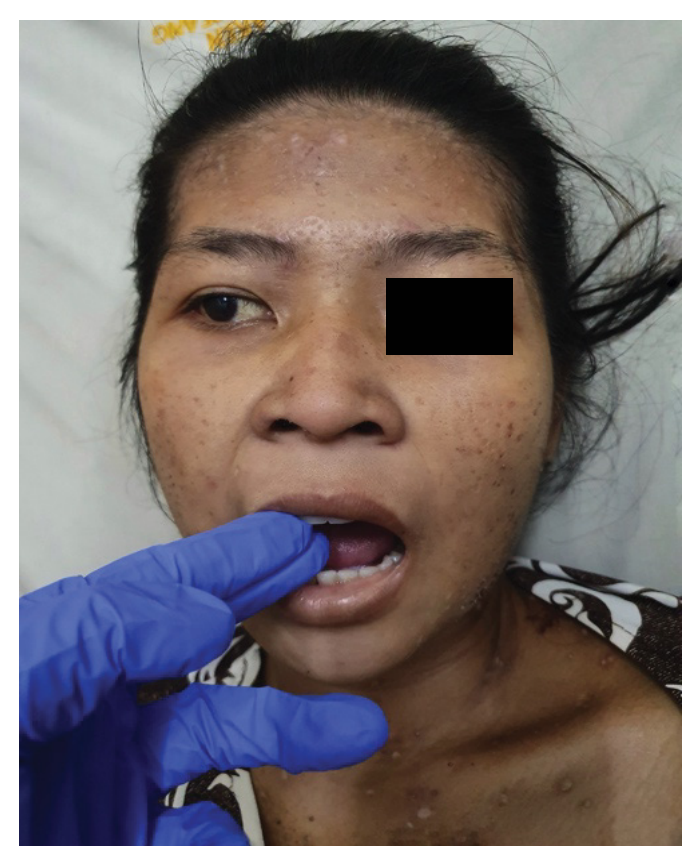

Figure 1: Two-finger trismus in the patient's mouth. There is a "salt and pepper" pattern with diffuse sclerosis of the frontal region.

The working diagnosis in this patient was diffuse systemic scleroderma with secondary infection based on physical examination. The assessment of the patient's disability and function was carried out using the Scleroderma Health Assessment Questionnaire (SHAQ) on the first day of treatment with a score of SSC HAQ 2, the interpretation of the results is that it is very difficult to carry out daily activities accompanied by very disturbing pain. Topical management for the skin is given mupirocin $2 \%$ cream every day and night which is applied to the skin with ectima, and vaseline album every morning and evening which is applied to the dry skin. Consul of Internal Medicine, the patient was given oral therapy methotrexate $15 \mathrm{mg} /$ week, clindamycin $4 \times 150 \mathrm{mg}$, and oral antihistamine cetirizine $1 \times 10 \mathrm{mg}$. Patients were also given fluid therapy, nifedipine $3 \times 5 \mathrm{mg}$, aspilet $1 \times 80$ $\mathrm{mg}$, methyl prednisolone $2 \times 4 \mathrm{mg}$, folic acid $1 \times 400$ $\mathrm{mcg}$, domperidone $3 \times 10 \mathrm{mg}$, and omeprazole $1 \times 40$ mg. Patients are given education to maintain skin cleanliness by taking regular baths every day (Figure 1, Figure 2, Figure 3, Figure 4 and Figure 5).

After being treated for 7 days, the patient was allowed to go home with a note to maintain routine control. On examination, the patient's general condition began to improve, the patient had started to eat small amounts of food frequently. Ectima begins to dry out even though there is still diffuse sclerosis of the patient's skin. The patient's skin is more moist than when she first came to the hospital and can walk slowly with a total mRSS of 32. In the second SHAQ assessment, SSC HAQ score of the patient is 1 with interpretation of the results of a little difficulty in carrying out daily activities accompanied by a little pain. 

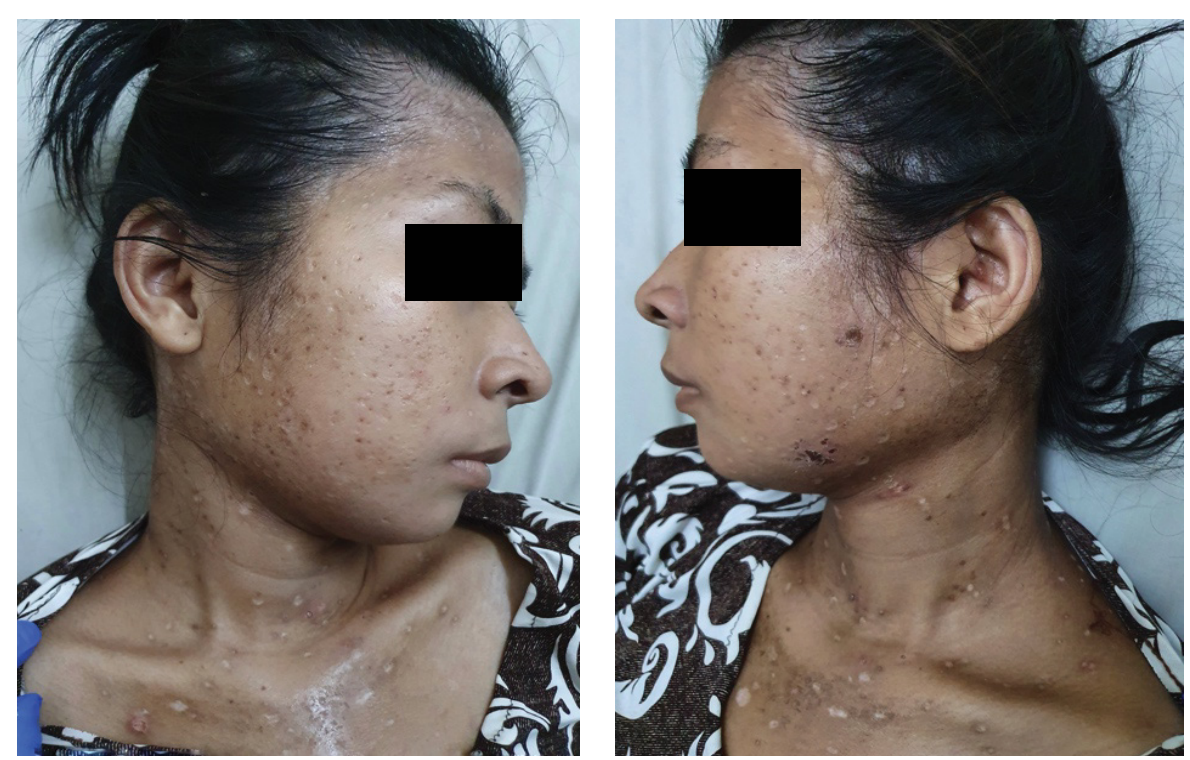

Figure 2: Photograph of the patient's right and left side of the head. There is a "salt and pepper" pattern and multiple ectima on the frontal pars, bilateral mastoid pars, and upper thorax.

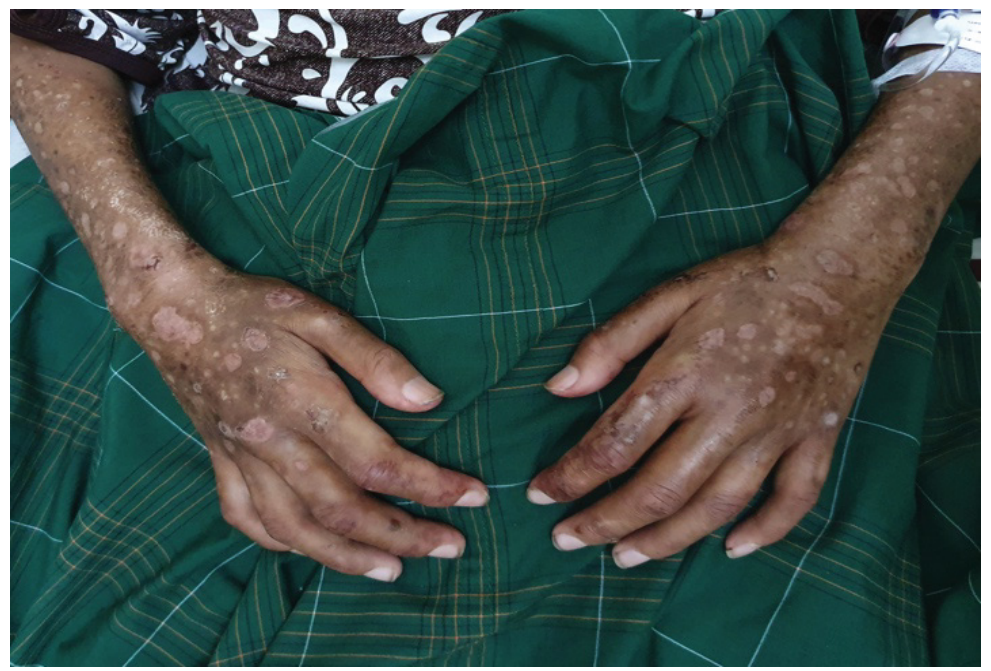

Figure 3: Multiple ectima on the forearm to bilateral manus accompanied by puffy fingers with sclerodactyly on all of the patient's fingers.
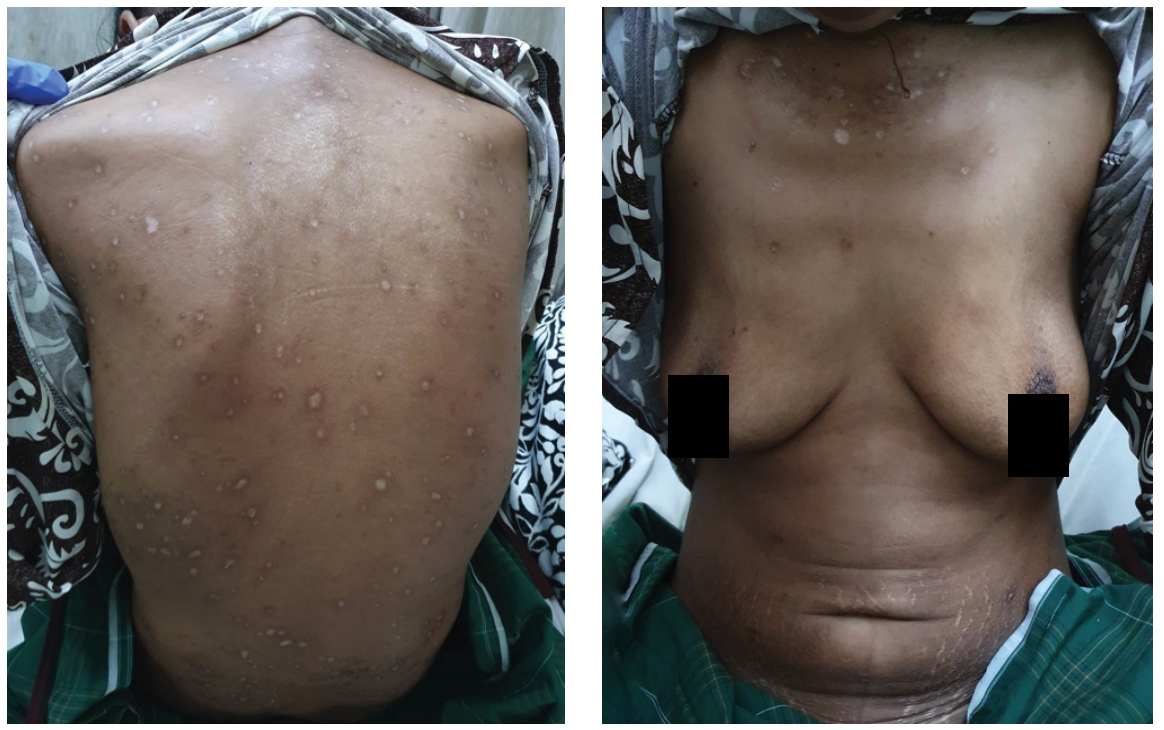

Figure 4: The back (left) and thoracoabdominal (right) show generalize ectima with diffuse sclerosis of the upper back and thorax. 


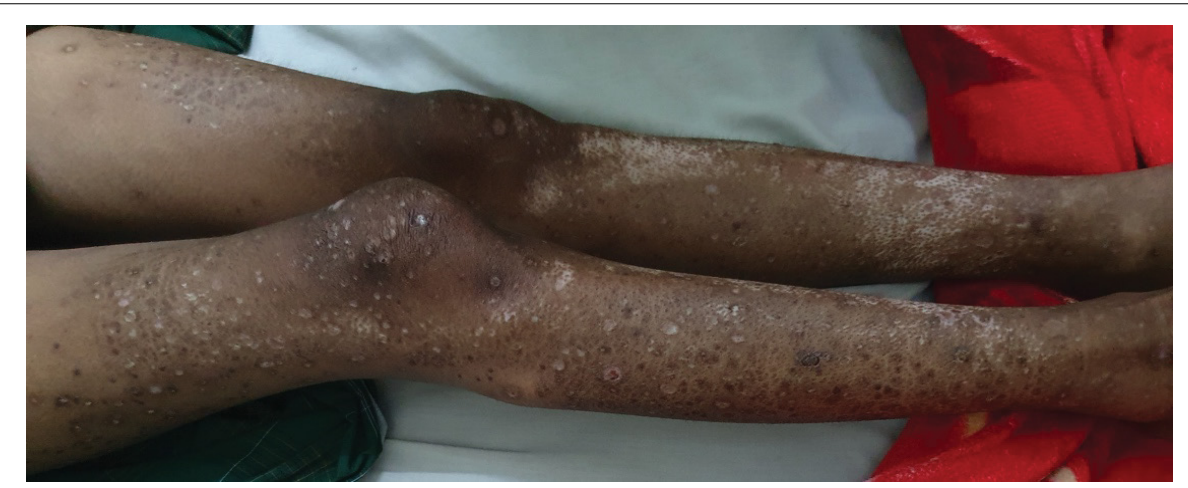

Figure 5: Photograph of both limbs. Diffuse sclerosis of the upper and lower limbs was seen with a "salt and pepper" pattern. Looks xerotic skin with multiple ectima.

\section{Discussion}

Scleroderma is a chronic multisystem disease whose cause is still unknown. Scleroderma is characterized by thickened skin due to the accumulation of connective tissue, accompanied by abnormalities in the function and shape of the visceral organs including the gastrointestinal tract, lungs, heart, and kidneys [1]. The prevalence of scleroderma is relatively low, children and young adults are rarely affected. The age of 30 to 50 years is the largest age in this disease. At the age of less than 16 years, the incidence is about 3\% of all cases of scleroderma [2]. Women are affected 3 to 4 times more often than men [1-3]. In this case, the patient is a 25-year-old woman who presents with tightened skin complaints. In this case the prevalence of women is according to cases, but the prevalence of age does not match because it is rare for women under 30-years-old.

Scleroderma diagnosis can be made based on history and physical examination. Symptoms for diagnosing scleroderma include extensive thickening of the skin, calcinosis of the cutis in the area of pressure, telangiectasias, and there are areas of skin with hyperpigmentation and hypopigmentation. Other complaints include difficulty opening the mouth (microstomy) and the "beak-shaped" nose [4]. Thickening of the skin in the scleroderma usually appears first on the hands and feet. In the early phases of scleroderma, there will be non-pitting edema in the patient's fingers (puffy fingers) accompanied by thickening of the skin which leads to sclerodactyly $[3,4]$. In this patient, the same complaints appear on both hands first, then to the two arms ,and another parts of the body. The patient experienced sclerodactyly and complaints of swollen fingers (puffy fingers). There is also a "salt and pepper" appearance pattern, which is a picture of hypo- and hyperpigmentation on the frontal pars, bilateral mastoid pars, bilateral neck, bilateral arms, chest, stomach, back, and bilateral legs. Loss of sweat glands in the patient was also obtained through history taking in which the patient rarely sweated. On physical examination, xerosis cutis was found. The patient also has difficulty opening his mouth, which makes it difficult for her to eat and clean her mouth.
Most of the sufferers have Raynaud's phenomenon (RP) which is a symptom of reversible peripheral arteriolar vasoconstriction, in response to cold or stress [5]. In this patient, the color changes of the fingertips on both hands when they are in cold will turn pale and sometimes bluish.

Thickening of the patient's skin causes the patient's joint mobility to decrease. The patient has difficulty standing, even holding objects with both hands, so it is difficult to eat and drink by herself. Skin involvement in scleroderma patients can be detected using several modalities, one of which is by using mRSS, however mRSS has several drawbacks including variable results among clinicians [6]. In mRSS there are 17 skin locations that must be assessed. A score of 1 is given if there is skin thickening, a score of 2 if there is skin thickening and cannot be pinched (pinch), and a score of 3 if there is skin thickening and fixed skin [6]. Measurement of skin thickness is used as an indicator of the degree of severity and risk of mortality in scleroderma patients, especially dcSSc. Increased skin thickness is associated with internal organ involvement and an increased risk of death. Improved skin thickness scores were associated with better outcomes. The baseline mRSS assessment of this patient was 40 . The final mRSS assessment of the patient after 7 days of treatment was 32 .

The initial mRSS assessment was performed as follows (Figure 6):

Scleroderma can affect several organs, namely the vascular, skin, muscles, gastrointestinal tract, respiration, heart, and kidneys. The organ with the most abnormalities was the gastrointestinal tract with a proportion of involvement of $65.2 \%$ [4]. The clinical symptoms that arise depend on the part of the gastrointestinal tract involved, from the mouth to the rectum and anus [4]. Gastrointestinal involvement in scleroderma increases the risk of malnutrition by $15 \%-85 \%$, it can also cause death in up to $20 \%$ of patients [7]. The manifestations are smooth muscle atrophy and fibrosis of the gastrointestinal wall [6]. Patients complain of difficulty opening the mouth, the stomach feels full easily when eating. The patient also feels nauseous and vomits easily. For 


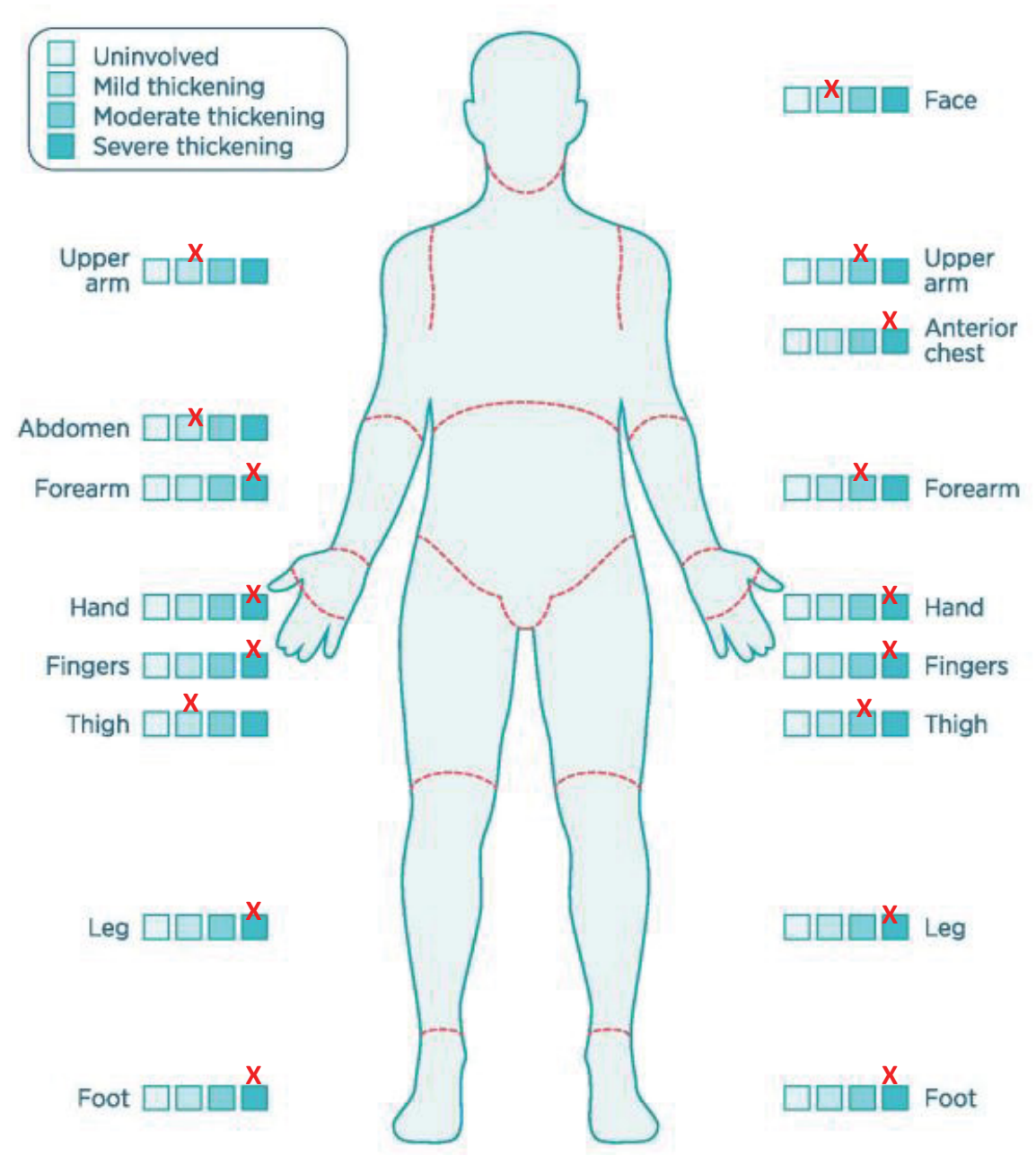

Figure 6: Intial mRSS assessment on case.

complaints of difficulty opening the patient's mouth, it can be helped by eating soft foods and maintaining oral hygiene to prevent oral candidiasis. Complaints that the stomach feels full when eating can be overcome by eating more often in small portions, and avoiding lying down 1-2 hours after dinner, or you can also avoid eating foods that relax the lower esophageal sphincter muscles such as chocolate, caffeine, mint, fruit juice, and fatty foods [7]. Based on the calculation of the patient's current BMI is still within normal limits, even though the patient has lost $20 \mathrm{~kg}$ of body weight in the last 6 months.

Generalized eczema in patients can be caused by vasoconstriction due to vascular sclerosis, so that the blood supply to the periphery of the skin decreases which makes it easy for skin bacteria (staphylococcus aureus) to grow $[4,11]$.

Patients denied other complaints such as coughing, shortness of breath, or heart palpitations. Physical examination, renal function, echocardiography, and chest radiograph of the patient were within normal limits.

There are several classification criteria used to enforce scleroderma. The first criteria were issued by the American College of Rheumatology (ACR) in 1980 [2]. The second criteria in 2013 were issued by ACR-EULAR
(American College of Rheumatology in collaboration with the European League Against Rheumatism) with more detailed criteria. Thickening of the proximal skin of the fingers of both hands extending to the metacarpophalangeal joints, Raynaud's phenomenon (RP), and anti-SCL-70 positive (+). So it can be concluded that the patient has systemic scleroderma with diffuse subclassification (dcSSc). In this patient a subclassification of $\mathrm{dcSSc}$ was considered because of the rapid disease progression in which the skin thickens $<1$ year, accompanied by RP. The skin lesions expand quite rapidly and involve almost all parts of the body. In addition, the ANA, RF (Rheumatoid Factor), and anti-Scl-70 tests gave positive results $[2,8]$.

ANA test using the Indirect Immunoflourescence (IIF Hep-2) method gives positive results in $60-90 \%$ of scleroderma sufferers. The picture or pattern seen in people with scleroderma varies, indicating that antibodies are present in the body. The specific autoantibodies for scleroderma are anti Scl-70 and anticentromer $[9,12,13]$. Anti Scl-70 is associated with diffuse and poor prognostic disease, whereas anticentromer is associated with limited skin involvement and provides a better prognosis, although sometimes overlapping [11]. Anti $\mathrm{Scl}-70$ is found in $40 \%$ of patients with diffuse systemic sclerosis (dcSSc), while limited systemic sclerosis (IcSSc) 
Scl-70 is only found in 10 to $15 \%$ of cases [9].

The Scleroderma Health Assessment Questionnaire (SHAQ) can be used to assess disability and function in patients with systemic sclerosis more specifically than the Health Assessment Questionnaire (HAQ) - Disability Index (DI) [10]. The SHAQ questionnaire consists of 20 HAQ-DI items with 5 additional visual analog domains score (VAS) that assess the pain symptoms in Reynaud's phenomenon, digitalis ulcers, gastrointestinal and pulmonary symptoms, and other comorbidities that interfere with patient activity $[10,14]$. HAQ-DI consists of 20 items divided into eight assessment domains, namely dressing, getting up, eating, walking, personal hygiene, reaching out, holding tight, and activity. The responses for each item consisted of "without difficulty (0)", "with little difficulty (1)", "with much difficulty (2)", and "unable to do (3)". The highest score in each domain is added and then divided by 8 to determine HAQ-DI. The final score will range between 0 and 3 . The higher the score indicates the higher the disability [10]. VAS assessments are conducted subjectively by the patient by marking a $15 \mathrm{~cm}$ long VAS line ranging from "unobtrusive" to "very disturbing". The VAS score is multiplied by 0.2 to get the final score. The scores range from 0 to 3 , representing the minimum to the maximum [10]. George, et al. [14] refer to these SHAQ scores as the "HAQ SSc Score", with scores ranging from 0 to 3 , which is a new measure for incorporating the five VAS domains into calculation. This new variable is calculated as follows: $\mathrm{SSC} H A Q$ score $=(8$ HAQ-DI domain score + 5 VAS domain score) divided by 13. SHAQ assessment was carried out on the first day of patient care with SSC HAQ score of 2 with very difficult interpretation of daily activities accompanied by a very disturbing pain. After 7 days of treatment, a second SHAQ assessment was carried out with a SSc HAQ score of 1 with the interpretation of a slight difficulty in carrying out daily activities with slightly disturbing pain.

The management of scleroderma is multidisciplinary, so that all organs that can be involved are screened. The therapy given is usually individual depending on the patient's needs given the potential for toxicity due to treatment. Scleroderma therapy is based on the main abnormalities, namely vascular, immunosuppressive, and antifibrotic $[4,5]$. The patient has received nifedipine therapy for vascular complaints, in this case is RP. Nifedipine has vasodilating and vascular remodeling effects. For antifibrotics the patient has received aspilet. The patient also received domperidone and omeprazole for the gastrointestinal tract complaints. Finally, the patient was also given a low dose of methyl predinisolone $(8 \mathrm{mg}$ ) to overcome the inflammatory process. For dry skin, feeling pulled or tight and itchy, the patient receives a vaseline album moisturizer and an antihitamin to reduce itching. While generalized ectima was given $2 \%$ mupirocin ointment with the oral antibiotic clindamycin $4 \times 150 \mathrm{mg}$. Self-moisturizing has been recom- mended by the British Society for Rheumatology and British Health Professionals in Rheumatology [5]. Meanwhile, systemic methotrexate therapy is given to reduce the severity of skin scores [15].

\section{Conclusion}

A case of a woman, 25-years-old, diagnosed with dcSSc with secondary infection based on history, clinical symptoms, and investigations has been reported. An assessment of the patient's disability and function was carried out using the Scleroderma Health Assessment Questionnaire (SHAQ) with the results of improvement for 7 days of treatment. The therapy given is only for improvement of the general condition and only reduces or eliminates complaints but does not cure. The prognosis in this patient is dubious, leading to night because complete remission is difficult to achieve in SSc cases.

\section{References}

1. Gilliland BC (2005) Systemic Sclerosis (Scleroderma) and Related Disorder In: Fauci AS (eds). Harrison's Prinsiples of Internal Medicine. (16 ${ }^{\text {th }}$ edn), New York, Mc Graw-Hill 1979-1990.

2. Setyohadi B, Sklerosis Sistemik Dalam Noer HMS, Waspadji S, Rachman AM dkk (2000) (eds). Buku ajar IImu Penyakit Dalam. Edisi ketiga. Jakarta, Balai Penerbit FKUI, 187-197.

3. Black CM (2002) Scleroderma and fasciitis in childhood. UpToDate 10: 998.

4. Moinzadeh P, Denton CP, Krieg T, Black CM (2012) Scleroderma. In: Goldsmith LA, Katz SI, Gilchrest BA, Paller A, Leffell D WK, Fitzpatrick's Dermatology in General Medicine. ( $8^{\text {th }}$ edn), New York: McGrawHill 1942-1956.

5. Denton CP, Hughes M, Gak N, Vila J, Buch MH, et al. (2016) BSR and BHPR guideline for the treatment of systemic sclerosis. Rheumatology (Oxford) 55: 1906-1910.

6. Raynaud's Association. Frequently Asked Question. Diunduh dari www.raynauds.org/frequently- asked-questions/ tanggal 8 January 2017.

7. Parrish CR (2016) Nutritional Implications of GI Related Scleroderma. Practical Gastroenterology 35-46.

8. Maartenskliniek S (2013) ACR/EULAR classification criteria for Systemic Sclerosis.

9. Eisenberg ME, Nguyen BY, Karnath BM (2008) Clinical Features of Systemic Sclerosis. Hospital Physician.

10. Defi IR, Jennie J, Vitriana V, Arisanti F (2014) Translation and Validation of Indonesian Version of Scleroderma Health Assessment Questionnaire. Majalah Kedokteran Bandung 52: 45-52.

11. Mayes MD, Whittum-Hudson JA, Oszust C, Gérard HC, Hudson AP (2009) Lack of evidence for bacterial infections in skin in patients with systemic sclerosis. Am J Med Sci. 337: 233-235.

12. Souza EJR, Kayser C (2015) Nailfold capillaroscopy: Relevance to the practice of rheumatology. Rev Bras Reumatol 55: 261-271.

13. Moinzadeh $P$, Denton $C P$, Abraham $D$, Ong $V$, Hunzelmann $\mathrm{N}$, et al. (2012) Biomarkers for skin involvement and fibrotic activity in scleroderma. Journal of the European Academy of Dermatology and Venereology 26: 267-276. 
14. Georges C, Chassany O, Mouthon L, Tiev K, Toledano C, et al. (2005) Validation of French version of the Scleroderma Health Assessment Questionnaire (SSc HAQ). Clin Rheumatol 24: 3-10.
15. Walker KM, Pope J (2012) Treatment of Systemic Sclerosis Complication: What to Use When First-Line Treatment Fails - A Consensus of Systemic Sclerosis Experts. Seminars in Arthritis and Rheumatism 42: 42-55. 